\title{
Biological Evaluation of Quaternary bis Ammonium Salt and Cetylpyridinum Bromide Against S. epidermidis Biofilm
}

\author{
JOANNA STEFAŃSKA ${ }^{1 *}$, ANNA PIETRUCZUK-PADZIK¹, MARTA STRUGA², MACIEJ BORKOWSKI ${ }^{3}$ \\ and STEFAN TYSKI ${ }^{1,4}$ \\ 'Department of Pharmaceutical Microbiology, Medical University of Warsaw, Poland \\ ${ }^{2}$ Department of Medicinal Chemistry, Medical University of Warsaw, Poland \\ ${ }^{3}$ Student Scientific Society at Department of Pharmaceutical Microbiology, Medical University of Warsaw \\ ${ }^{4}$ Department of Antibiotics and Microbiology, National Medicines Institute, Warsaw, Poland
}

Submitted 25 January 2013, accepted 18 October 2013

\begin{abstract}
Quaternary ammonium compounds are broad-spectrum bacteriocides widely used as antiseptics, disinfection and preservation agents. The aim of this study was to examine the activity of two quaternary ammonium salts, cetylpyridinum bromide and a newly synthesized quaternary bis ammonium salt, against $S$. epidermidis biofilm. The average values of killing efficiency for cetylpyridinum bromide ranged from $26.6 \%$ to $64.1 \%$ for all tested concentrations $\left(0.125\right.$ to $\left.8.0 \mu \mathrm{g} \times \mathrm{mL}^{-1}\right)$ and for quaternary bis ammonium salt the percentage of killing efficiency ranged from $59.7 \%$ to $88.4 \%$ for tested concentrations (from 2.0 to $128.0 \mu \mathrm{g} \times \mathrm{mL}^{-1}$ ). Both tested compounds significantly affect staphylococcal biofilms, but any of used concentrations caused a total eradication of bacterial biofilm.
\end{abstract}

Ke y wo r d s: bacterial biofilm, Staphylococcus epidermidis, quaternary ammonium compounds

\section{Introduction}

Many strains of Gram-positive bacteria are dangerous pathogens causing severe hospital infections. Apart from infections of clean wounds, the special attention should be paid to infections occurring in patients who have received implants, i.e. valves, vascular and bone implants, joint prostheses, or tendon prostheses made of biomaterials (Wójcikowka-Mach et al., 2002; Christensen, 1982; Götz, 2002; Mack et al., 2006). Due to the incorrect use of antiseptics before and after surgery, colonisation of the surgical wound by the microbes originating from the hospital environment, occurs quite frequently. Microbes also can be transmitted from the hands of the medical personnel, or transferred from the patient's skin, and cause an endogenic infection. Another source of potential pathogens are microbes that colonise the applied vascular and urinary catheters, drainage tubes, respiration aids as well as other therapeutic and diagnostic equipment (Trautner et al., 2004; Pascual, 2002). The most common etiologic factors that bring about infections of operated tissue are Staphylococcus aureus, Escherica coli, Pseudomonas spp., Klebsiella spp., Enterobacter spp., Bacteroides spp., Candida albicans. In orthopedic patients, due to a broad use of biomaterials, 55\% of infection is caused by Staphylococcus epidermidis, and $10-20 \%$ by Staphylococcus aureus (Arciole et al., 2005; Husain et al., 1993; Huebner et al., 1990). In fact, S. aureus is an important cause of infection associated with use of metal implants, bone and joint prostheses and cause a soft tissue infections, while S. epiermidis is seen more often in polymer-associated infections (Götz, 2002). Staphylococcus epidermidis growing as biofilm is often very resistant to conventional antibiotics, antiseptics and disinfectants (Bridier et al., 2011, Smith et al., 2008). The values of minimal inhibitory concenrtation (MIC) and minimal bactericidal concentration (MBC) of antibiotics to bacteria grown in biofilm, may by up to 1000 -fold higher compared with bacteria in planktonic form (Høiby et al., 2010). Currently no therapies that target microbial biofilm exist; therefore, new antibiofilm agents, treatments and strategies are needed. The discovery of new antimicrobial agents, active not only against free-swimming microorganisms (planktonic) but also against biofilms, represents an important task (Projan et al., 2002; Karpanen et al., 2008). With this aim, we focused on quaternary ammonium salts

* Corresponding author: J. Stefańska, Department of Pharmaceutical Microbiology, Medical University of Warsaw, 3 Oczki Str., 02-007 Warsaw, Poland; phone: +48 22 6280822; fax: +48 22 6211351; e-mail: joanna.stefanska@wum.edu.pl 
that represent a class of biologically active substances, primary acting as antimicrobial agent (Høiby et al., 2010; Chaieb etal., 2011). Quaternary ammonium compounds are a broad-spectrum bactericides widely used as antiseptics, disinfection and preservation agents (Russel, 2003). The activity of quaternary ammonium compounds, especially the role of long chain against different bacteria, has been previously observed. The positively charged quaternary nitrogen with the polar head groups of acidic phospholipids cause perturbation of cytoplasmic and outer membrane lipid bilayers. Long chain exert antibacterial activity against both Grampositive and Gram-negative bacteria as well as against some pathogenic species of fungi and protozoa (Ancelin et al., 2003; Ioannou et al., 2007; McBain et al., 2004)

The aim of this study was to examine the activity of two quaternary ammonium salts against a group of S. epidermidis strains isolated from patients hospitalized in the clinical hospital in Warsaw. These strains growing as plankton, as well as a biofilm structure, were under evaluation. One of the tested compounds was hexadecylpyridinium bromide (cetylpyridinum bromide), widely known substance with antimicrobial properties widely used as an antiseptic. The second substance was a newly synthesized derivative: bis-[2-hydroxy3-(1,7,8,9,10-pentamethyl-3,5-dioxo-4-aza-tricyclo[5.2.1.0(2,6)]dec-8-en-4-yloxy)-propyl]-dimethylammonium chloride (quaternary bis ammonium salt). Generally used quaternary ammonium salts are slightly soluble in water. Newly obtained quaternary bis ammonium salt applied to the tests, has a hygroscopic properties and as very high solubility in the water, so may be used without addition of ethanol to the tested solution.

Synthesis method and basic antimicrobial activity of this agent were previously described (Struga et al., 2008).

\section{Experimental}

\section{Materials and Methods}

Chemicals. Cetylpyridinum bromide (Sigma) is a known cationic quaternary ammonium compound with antimicrobial activities.

Synthesized quaternary bis ammonium salt was obtained in four steps. First the starting compound (1,2,3,4,5-pentamethylcyclopentadiene) was heated with maleic anhydride. The obtained compound was subjected to the reaction with hydroxylamine hydrochloride in water solution. The product was alkylated with 2-chlorometyl-oxirane and then it was condensed with dimethylamine. Resulting compound was transformed into quaternary ammonium salt by $\mathrm{HCl}$ saturated methanol treatment.

Bacterial strains. Twenty three clinical Staphylococcus epidermidis and one reference strain S. epider- midis ATCC 12228 were used in this study. The clinical strains were isolated from following locations: blood $(n=20)$, catheter $(n=2)$ and venous catheter $(n=1)$. S. epidermidis strain ATCC 12228 was used in biofilm assay as a negative control (biofilm non-producing strain). The antibiotic susceptibility of the tested strains was determined by the standard CLSI disk diffusion method (CLSI, 2006a). Twenty one of clinical strains were methicillin-resistant (MRSE). Fifteen strains were resistant to erythromycin, eight - to clindamycin, five - to gentamicin, two - to amikacin, seven - to co-trimoxazole, six - to ciprofloxacin, three - to tetracycline. All strains were susceptible to linezolid.

Microorganisms were derived from the collection of Department of Pharmaceutical Microbiology, Medical University of Warsaw, Poland.

Antibacterial susceptibility testing - MIC method. The minimum concentrations of both tested quaternary ammonium compounds inhibiting growth of S.epidermidis strains (MICs) were determined by reference broth dilution methods using Mueller-Hinton II Broth, according to Clinical and Laboratory Standards Institute guidelines (CLSI, 2006b).

Concentrations of tested compounds in liquid medium ranged from 0.0625 to $256 \mu \mathrm{g} \times \mathrm{mL}^{-1}$, cetylpyridinum bromide was dissolved in $50 \%$ ethanol, quaternary bis ammonium salt - in distillated water. The final inoculum of all microorganisms studied was about $10^{4} \mathrm{CFU} \times \mathrm{mL}^{-1}$ (colony forming units per $\mathrm{mL}$ ). MICs were read after $18 \mathrm{~h}$ incubation at $35^{\circ} \mathrm{C}$. The MIC values determined in susceptibility test on planktonic bacteria were applied also during staphylococcal biofilm susceptibility determination.

S. epidermidis biofilm susceptibility testing - MTT method. All strains were kept frozen at $-70^{\circ} \mathrm{C}$ in $\mathrm{BHI}$ broth supplemented with $10 \%$ glycerol, until use. The strains were first grown from a frozen stock on BHI agar plates by incubation during $24 \mathrm{~h}$ at $37^{\circ} \mathrm{C}$. Bacterial colonies were harvested, and suspended in $0.85 \%$ $\mathrm{NaCl}$ to prepare cells suspensions for biofilm production. The density of all cell suspensions was adjusted to the value of 3.2 units in McFarland scale, which was equal to $10^{9} \mathrm{CFU} \times \mathrm{mL}^{-1}$. Each inoculum was diluted 1 to 10 with fresh BHI broth. Individual wells of polystyrene, sterile 96-well tissue culture plates (Kartell S.p.A., Medlab, Italy), were filled up with $200 \mu \mathrm{l}$ of diluted cultures and incubated for $24 \mathrm{~h}$ at $37^{\circ} \mathrm{C}$. Additionally $200 \mu \mathrm{l}$ of BHI medium was added to some wells, as control of sterility and non-specific media binding. After incubation planktonic cells were removed and bacterial biofilm layer was treated with quaternary bis ammonium salt at concentrations ranging from 2.0 to $128.0 \mu \mathrm{g} \times \mathrm{mL}^{-1}$. For comparative and quality control purposes, other wells with biofilm were treated with quaternary ammonium derivative - cetylpirydinium 
bromidum - at concentrations from 0.125 to $8.0 \mu \mathrm{g} \times$ $\times \mathrm{mL}^{-1}$. The plates were incubated with these compounds for $18 \mathrm{~h}$ at $37^{\circ} \mathrm{C}$. Following incubation period, the analyzed compounds were removed from the microplate wells and they were washed with sterile phosphate buffer saline (PBS). Alive bacterial cells were stained with 3-(4,5-dimethyl-2-thiazolyl)-2,5 diphenyl-2H-tetrazolium bromide (MTT; 0.5\% in PBS) for 2 hours at $37^{\circ} \mathrm{C}$. In parallel, appropriate bacterial biofilm not treated with these two compounds was used as a control. $\Lambda \mathrm{fter} 2 \mathrm{~h}$ of staining, solution was removed and biofilm was solubilized by $150 \mu \mathrm{l}$ DMSO with $25 \mu \mathrm{l}$ glicyne buffer $\left(0.1 \mathrm{M} \times \mathrm{L}^{-1}, \mathrm{pH} 10.2\right)$ treatment. Solution absorbance was measured at $554 \mathrm{~nm}$ wavelength using a PowerWave XS (BioTek) spectrophotometer.

Comparing the average results of absorbance $\left(\mathrm{A}_{554}\right)$ of the control biofilm with the biofilm treated with tested compounds, the percentage of killing efficiency for each concentration and for each strain, was calculated by the following formula:

$$
\text { Percentage of killing efficiency }=\frac{\mathrm{A}_{554} \text { control biofilm }-\mathrm{A}_{554}}{\mathrm{~A}_{554} \text { control biofilm }} \times 100 \%
$$

\section{Results}

The MIC values for the cetylpyridinum bromide for planktonic cells ranged from $0.125 \mu \mathrm{g} \times \mathrm{mL}^{-1}$ to $8.0 \mu \mathrm{g} \times \mathrm{mL}^{-1}$. For the almost half of strains (11/24-46\%) the MIC value was $2.0 \mu \mathrm{g} \times \mathrm{mL}^{-1}$. For the references strain S.epidermidis (ATCC 12228) this value was $0.125 \mu \mathrm{g} \times \mathrm{mL}^{-1}$. Only for the one tested strain MIC value was $8.0 \mu \mathrm{g} \times \mathrm{mL}^{-1}$. For the quaternary bis ammonium salt MIC values for the planktonic cells ranged from $16.0 \mu \mathrm{g} \times \mathrm{mL}^{-1}$ (only one - references strain) to $128.0 \mu \mathrm{g} \times \mathrm{mL}^{-1}(14 / 24-58.3 \%)$.

The average value of absorbance was calculated for each strain, after treatment of tested compounds.

Analysis of results for testing strains during experiment with cetylpyridinum bromide, allowed to classify these strains as low, intermediate and high biofilm producers, depending on absorbance value. The absorbance levels $\left(\mathrm{A}_{554}\right)$ were assumed subjectively by authors in order to classify the analysed strains into 3 groups of different biofilm production level. First group: high biofilm producers - absorbance values above 1.5; second group: intermediate biofilm producers - absorbance 1.0-1.5, and third group: low biofilm producers - absorbance below 1.0. Only few (3/24) strains were classified as high biofilm producers, whereas 13 of tested strains displayed low biofilm production phenotype. The second group of eight strains, including S. epidermidis ATCC 12228, previously described as non-biofilm producer [23]. Average absorbance value for this strain was 1.172 .

The percentage of killing efficiency was calculated for each strain. In $0.125 \mu \mathrm{g} \times \mathrm{mL}^{-1}$ concentration of cetylpyridinum bromide, the percentage of killing efficiency was $43.6 \%$ for the first group of strains, $62.7 \%$ for second group, and $44.7 \%$ for third group. In the highest concentration $8.0 \mu \mathrm{g} \times \mathrm{mL}^{-1}$ this efficiency was $48.3 \%, 64.1 \%$ and $47.0 \%$ respectively. Medium values of killing efficiency ranged from $26.6 \%$ to $64.1 \%$ for all tested concentrations in three groups of strains. The most sensitive for cetylpyridinum bromide were strains from intermediate biofilm producers group (48.6-64.1\% of killing efficiency). The most resistant were bacterial strains from third group - low biofilm producers (26.6 to $47.0 \%$ of killing efficiency). For

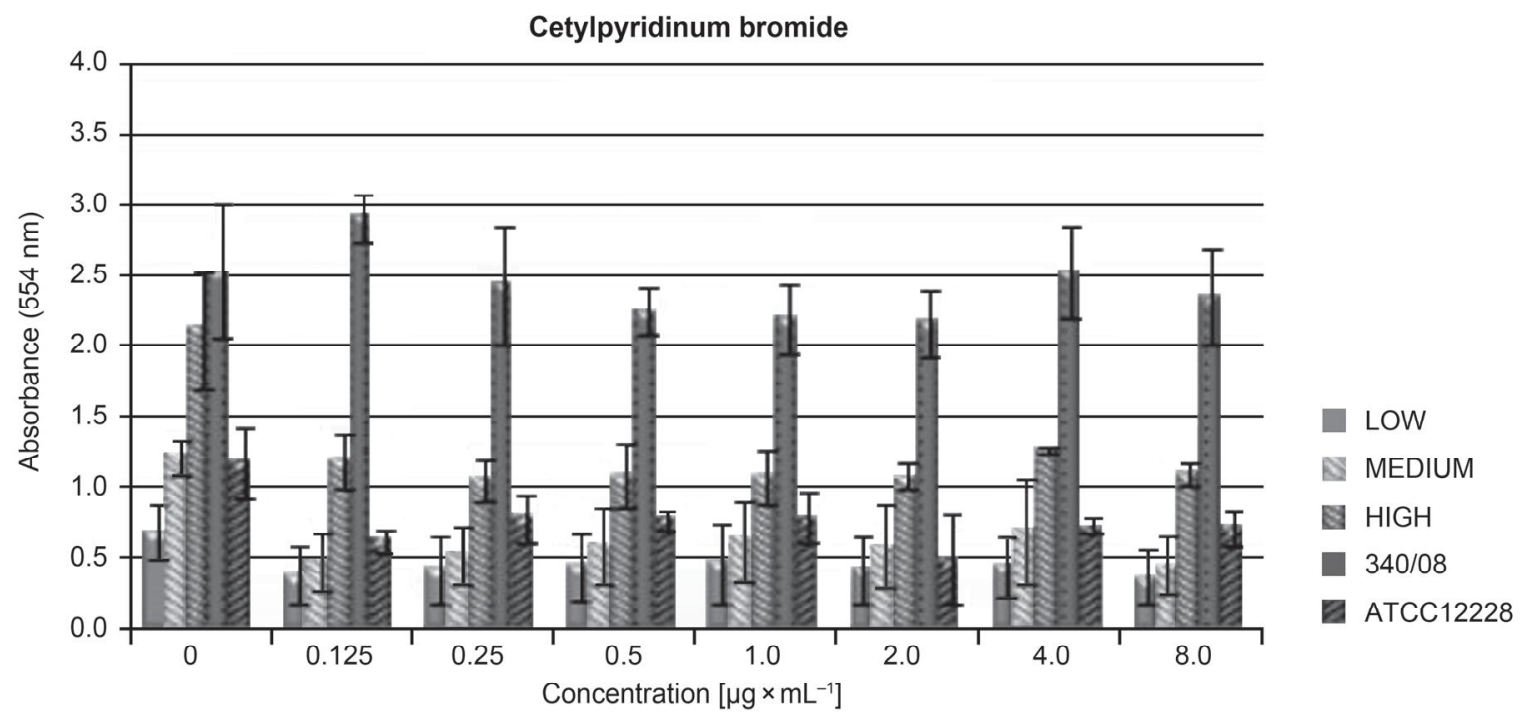

Fig. 1. Values of biofilm absorbance of $S$. epidermidis strains groups: low biofilm producers $\left(A_{554}<1.0\right)$, medium biofilm producers $\left(A_{554} 1.0-1.5\right)$, high biofim producers $\left(A_{554}>1.5\right)$, strain 340/08 and references strain ATCC 12228, after treatment with cetylpyridinum bromide. 


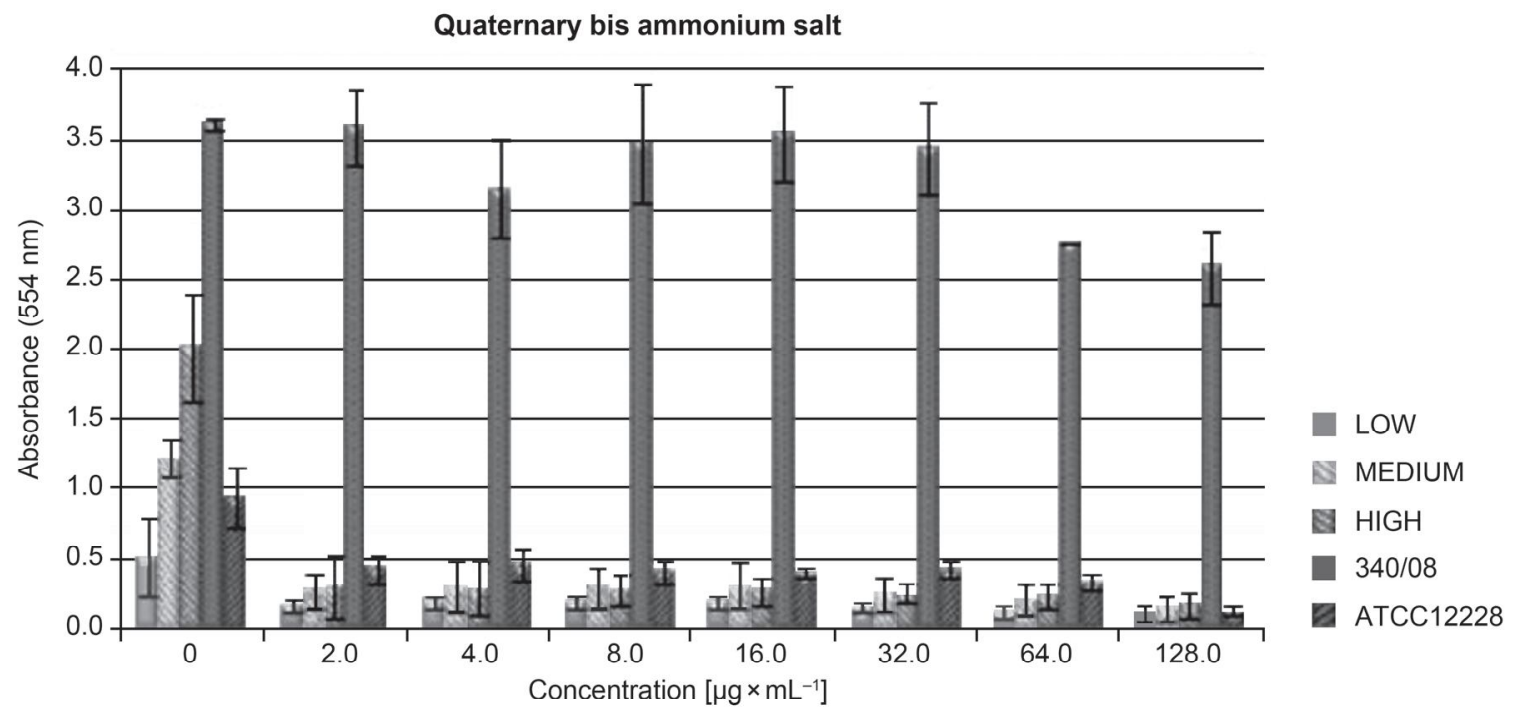

Fig. 2. Values of biofilm absorbance of $S$. epidermidis strains groups: low biofilm producers $\left(A_{554}<1.0\right)$, medium biofilm producers $\left(A_{554} 1.0-1.5\right)$, high biofim producers $\left(A_{554}>1.5\right)$, strain 340/08 and references strain ATCC 12228, after treatment with quaternary bis ammonium salt.

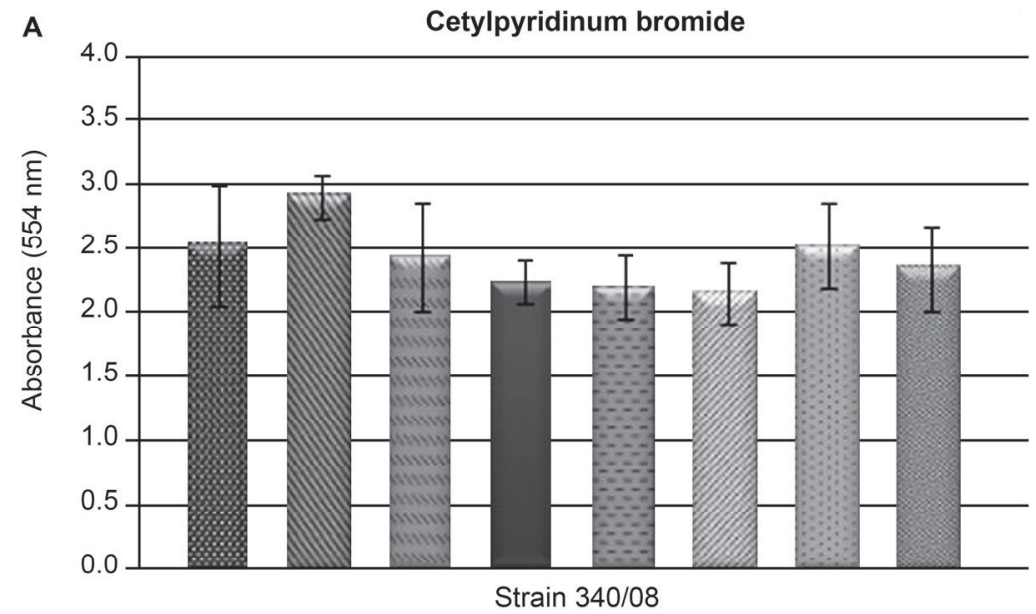

concentration $\left[\mu \mathrm{g} \times \mathrm{mL}^{-1}\right]$

B

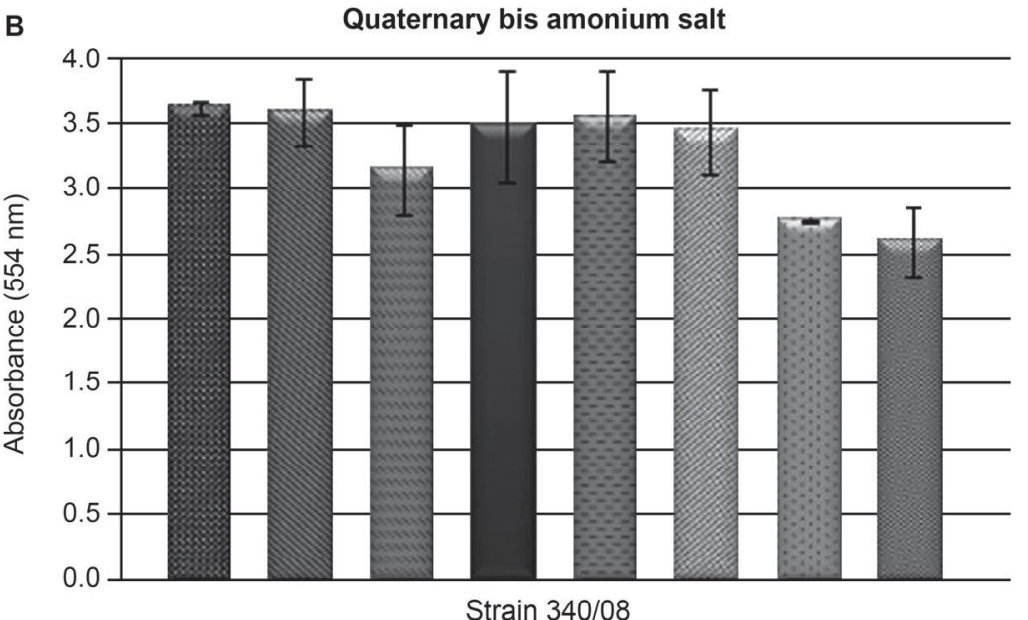

control

MV 0.125

0.25

0.5

$=1.0$

2.0

4.0

8.0

concentration $\left[\mu \mathrm{g} \times \mathrm{mL}^{-1}\right]$

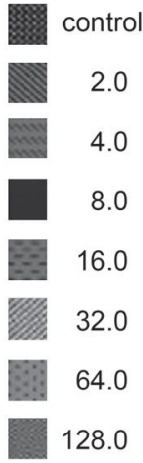

Fig. 3. Values of biofilm absorbance of S. epidermidis strain 340/08, after treatment with cetylpyridinum bromide (A) and quaternary bis ammonium salt (B).

strains from the second and third group the most effective concentration was $8.0 \mu \mathrm{g} \times \mathrm{mL}^{-1}$, while for the first group the most effective was $0.25 \mu \mathrm{g} \times \mathrm{mL}^{-1}$. For the all tested S. epidermidis strains the most effective was the highest used concentration $-8.0 \mu \mathrm{g} \times \mathrm{mL}^{-1}$ (average about $53 \%$ of killing efficiency) (Fig. 1). 
These results showed that cetylpyridinum bromide is activity towards S. epidermidis biofilm in vitro, regardless of the concentration. None of the concentrations used caused total eradication of staphylococcal biofilm, but the clear limiting effect on the growth was observed.

During the experiment with quaternary bis ammonium salt the analyzed strains were again classified to three biofilm producers groups, as it was described above. In this part of research some strains were classified to different group as it was previously. To first group - high biofilm producers 9 strains were classified, to second-intermediate biofilm producers -9 strains, and to third - low biofilm producers -6 strains. The references strain in this part displayed low biofilm producers phenotype (average absorbance value 0.943 ).

For each strain the percentage of killing efficiency for quaternary bis ammonium salt was also calculated. Average killing efficiency ranged from 59.7 to $88.4 \%$ for tested concentrations (from 2.0 to $128.0 \mu \mathrm{g} \times \mathrm{mL}^{-1}$ ) in all groups. The intermediate biofilm producers $(74.3$ to $88.4 \%$ of killing efficiency) were the most sensitive to this compound, while the low biofilm producer strains were the most resistant (59.7 to $80.3 \%$ ). For all tested strains the most effective concentration was $128.0 \mu \mathrm{g} \times \mathrm{mL}^{-1}$ (Fig. 2).

Among most of tested strains increased concentration of quaternary bis ammonium salt, caused higher anti-biofilm efficiency. The most resistant strain for cetylpyridinum bromide and quaternary bis ammonium salt treatment was strain 340/08 (Fig. 3). Only the highest concentrations of quaternary bis ammonium salt slight decrease of absorbance values, and thus decreased of quantity of viable bacterial cells. For cetylpyridinum bromide was not observed such a clear effect on bacterial biofilm.

\section{Discussion}

In this study two quaternary ammonium salts were examined against planktonic cells and biofilm of clinical Staphylococcus epidermidis strains. Cetylpyridinum bromide is widely used as an antiseptic compound. The second analyzed agent - newly synthesized derivative called quaternary bis ammonium salt.

There was no previous reports about activity of these two compounds against S.epidermidis biofilm and planktonic cells. Most of publications are focused on other widely used, chemical antiseptics - chlorhexidine, triclosan, alcohols, benzalkonium chloride (Karpanen et al., 2008; Chaieb et al., 2011; Russel, 2003; Ioannou et al., 2007). During this study cetylpyridinum bromide proved to be more effective compound, compared with a newly synthesized quaternary bis ammonium salt. Activity of this derivative towards planktonic bacteria was comparable with commonly used triclosan and chlorhexidine. However, MICs values for quaternary bis ammonium salt showed, that it can also act a very effective antimicrobial agent. It has been shown that cetylpyridinium chloride for example used in mouth rinsing preparations, interacts strongly with Streptococcus mutans biofilm. This compound diffuses slowly in biofilm structures and appears to bioaccumulate forming a structure that practically cannot be washed out from biofilm (Marcotte et al., 2004).

Biofilm development is a dynamic and variable process, dependent on many different external factors, and it is nearly practicaly impossible to obtain in vitro in a reproducible manner biofilm level from the same strain. S. epidermidis biofilms were more resistant to both of used compounds compared to planktonic form of the same strains. None of the tested compounds was able to completely eradicate the biofilms structures attached to surface of polystyrene plate wells.

Smith and Hunter (Smith et al., 2008) conducted a study on the effects of $1 \%$ benzalkonium chloride, $4 \%$ chlorhexidine digluconate and $1 \%$ triclosan against biofilm formed by clinical multidrug resistant izolates of S. aureus and P. aeruginosa. The same concentrations of tested compounds were chosen as used for disinfection in hospitals. For these compounds the killing efficiency was: for S. aureus - from $89 \%$ to $100 \%$, for P. aeruginosa - about 20\% (Smith et al., 2008). The results from this study show, that bacterial cells in biofilm structure are very resistant, despite that concentrations of tested compounds were highest than used in our study.

Investigation on the bactericidal activity of the tested compounds: cetylpyridinum bromide and a newly synthesized derivative: quaternary bis ammonium salt, against biofilms of S. epidermidis strains, confirmed the literatures data (Smith et al., 2008; Chaieb et al., 2011). Bacteria present in the biofilm exhibit significantly greater resistance for antibacterial agents, in comparison with planktonic forms of the same strains.

None of these compounds caused total eradication of staphylococcal biofilm in all tested concentrations.

\section{Literature}

Ancelin M.L., M. Calas, A. Bonhoure, S. Herbute and H.J. Vial. 2003. In vivo antimalarial activities of Mono- and Bis Quaternary Ammonium Salts Interfering with Plasmodium Phospholipid Metabolism. Antimicrob. Agents Chemother. 47: 2598-2605.

Arciole C. and D. Compaccio. 2005. Antibiotic resistance in expolysaccharide-forming Staphylococcus epidermidis clinical isolated from orthopedic implant infections. Biomaterial. 26: 6530-6535.

Bridier A., R. Briandet, V. Thomas and F. Dubois-Brissonnet. 2011. Resistance of bacterial biofilms to disinfectants: a review. Biofouling. 27: 1017-1032.

Chaieb K., T. Zamantar, Y. Souiden, K. Mahdouani and A. Bakhrouf. 2011. XTT assay for evaluating the effect of alcohols, 
hydrogen peroxide and benzalkonium chloride on biofilm formation of Staphylococcus epidermidis. Microb. Pathog. 50: 1-5.

Christensen G. 1982. Adherence of slime-producing strains of Staphylococcus epidermidis to smooth surfaces. Infection and Immunity. 37: 318-326.

Clinical and Laboratory Standards Institute. 2006 (a). Performance Standards for Antimicrobial Disk Susceptibility Tests; Approved Standard M2-A-9. Clinical and Laboratory Standards Institute, Wayne, Pa. USA.

Clinical and Laboratory Standards Institute. 2006 (b). Methods for Dilution Antimicrobial Susceptibility Tests for Bacteria That Grow Aerobically; Approved Standard-Seventh Edition. CLSI document M7-A7. Clinical and Laboratory Standards Institute, Wayne, Pennsylvania 19087-1898 USA.

Götz F. 2002. Staphylococcus and biofilms. Mol. Microbiol. 43: 1367-137.

Høiby N., T. Bjarnsholt, M. Givskov, S. Molin and O. Ciofu. 2010. Antibiotic resistance of bacterial biofilms. Int. J. Antimicrob. Agents. 35: 322-332.

Huebner J. and A. Goldman. 1990. Cagulase-negative Staphylococci: role as pathogens, Annu. Rev. Med. 50: 223-236.

Husain M., M. Wilcox M. and P. White. 1993. The slime of coagulose negative staphylococci: biochemistry and relaton to adherence. FEMS Microbiol. Rev. 103: 191-2008.

Ioannou C.J., G.W. Hanlon and S.P. Denyer. 2007. Action of Disinfectant Quaternary Ammonium Compounds against Staphylococcus aureus. Antimicrob. Agents Chemother. 51: 296-306.

Karpanen T.J., T. Worthington, E.R. Hendry, B.R. Conway and P.A.Lambert. 2008. Antimicrobial efficacy of chlorhexidine digluconate alone and in combination with eucalyptus oil, tea tree oil and thymol against planktonic and biofilm cultures of Staphylococcus epidermidis. J. Antimicrob. Chemother. 62: 1031-1036.

Los R., R. Sawicki, M. Juda, M. Stankevic, P. Rybojad, M. Sawicki, A. Malm and G. Ginalska. 2010. A comparitive analysis of phe- notypic and genotypic methods for the detrmination of biofilmforming abilities of Staphylococcus epiderrmidis. FEMS Microbiol. Lett. 310: 97-103.

Mack D., H. Rohde, L.G. Harris, A.P. Davies, M.A. Horstkotte and J.K. Knobloch. 2006. Biofilm formation in medical device-related infection. Int. J. Artif. Organs. 29: 343-359.

Marcotte L., H. Therien-Aubin, C. Sandt, J. Barbeau and M. Lafleur. 2004. Solute size effects on the diffusion in biofilms of Streptococcus mutans. Biofouling. 20: 189-201.

McBain A.J., R.G. Ledder, L.E. Moore, C.E. Catrenich and P. Gilbert. 2004. Effects of Quaternary-Ammonium-Based Formulations on Bacterial Community Dynamics and Antimicrobial Susceptibility. Appl. Environ. Microbiol. 70: 3449-3456.

Pascual A. 2002. Pathogenesis of catherer-related infection; lessons for new design. Clin. Microbiol. Infect. 8, 256-264.

Projan S.J. and P.J. Youngman. 2002. Antimicrobials: new solutions badly needed. Curr. Opin. Microbiol. 5: 463-465.

Russell A.D. 2003. Biocide use and antibiotic resistance: the relevance of laboratory findings to clinical and environmental situations. Lancet Infect. Dis. 3:794-803

Smith K. and I.S. Hunter. 2008. Efficacy of common hospital biocides with biofilms of multi-drug resistant clinical isolates. J. Med. Microb. 57: 966-973.

Struga M., Kossakowski J., Stefańska J., Zimniak A., Kozioł A.E. 2008. Synthesis and antibacterial activity of bis-[2-hydroxy3-(1,7,8,9,10-pentamethyl-3,5-dioxo-4-aza-tricyclo[5.2.1.02,6]dec8-en-4-yloxy)-propyl]-dimethyl-ammonium chloride. Eur. J. Med. Chem. 43: 1309-1314.

Trautner B.W., Darouiche R.O. 2004. Catheter-associated infections: pathogenesis affects prevention. Arch. Intern. Med. 164: 842-850.

Wójcikowska-Mach J., A. Różańska and M. Bulanda. 2002. Nadzór epidemiologiczny nad zakażeniem miejsca operowanego. Zakażenia 3-4: 5-17. 